\title{
EXPRESSION OF THE APOPTOSIS REGULATORY GENE FAMILY IN THE LONG-TERM IN VITRO CULTURED HUMAN CUMULUS CELLS
}

Rafał Sibiak $^{1,2}$, Rut Bryl ${ }^{3}$, Katarzyna Stefańska ${ }^{1}$, Błażej Chermuła ${ }^{4}$, Wojciech Pieńkowski ${ }^{5}$, Michal

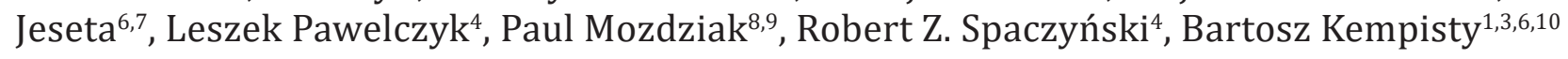

\begin{abstract}
Human cumulus cells (CCs) play a key role in the regulation of ovarian follicle maturation and oocyte fertilization. They influence the oocyte development by transferring the various molecules via the specific gap junction proteins, also known as the connexins, which provide a direct transmembrane connection between the oocyte and CCs. The human CCs were obtained in the patients diagnosed with infertility, who underwent the procedure of the controlled ovarian stimulation, and the following in vitro fertilization to elucidate the possible involvement of the CCs in the regulation of the fertilization and oocyte aging. Collected samples were long-term cultured and harvested after 7, 15, and 30 days of cultivation. Afterward, we assessed the relative expression of the following apoptosis regulatory genes - BAX, CASP9, and TP53 - using the RT-qPCR method. We noted a decrease in the expression of all above-mentioned genes in the samples harvested after 15 and 30 days, in reference to 7 days in vitro cultured CCs. In summary, our results provide precious insight into the dynamics of changes and confirm the continuous expression of the proapoptotic genes - BAX, CASP9, and TP53 in the long-term cultured CCs.
\end{abstract}

Running title: Apoptotic gene expression in the human cumulus cells

Keywords: apoptosis, BAX, CASP9, cumulus cells, oocyte, TP53

\footnotetext{
${ }^{1}$ Department of Histology and Embryology, Poznań University of Medical Sciences, Poznań, Poland

${ }^{2}$ Department of Reproduction, Chair of Obstetrics, Gynecology, and Gynecologic Oncology, Poznań University of Medical Sciences, Poznań, Poland ${ }^{3}$ Department of Anatomy, Poznań University of Medical Sciences, Poznań, Poland

${ }^{4}$ Division of Infertility and Reproductive Endocrinology, Department of Gynecology, Obstetrics and Gynecological Oncology, Poznań University of Medical Sciences, Poznań, Poland

${ }^{5}$ Division of Perinatology and Women's Diseases, Poznań University of Medical Sciences, Poznań, Poland

${ }^{6}$ Department of Obstetrics and Gynecology, Faculty of Medicine, Masaryk University and University Hospital Brno, Brno, Czech Republic

${ }^{7}$ Department of Veterinary Sciences, Czech University of Life Sciences in Prague, Prague, Czech Republic

${ }^{8}$ Physiology Graduate Program, North Carolina State University, Raleigh, NC, USA

${ }^{9}$ Prestage Department of Poultry Science, North Carolina State University, Raleigh, NC, USA

${ }^{10}$ Department of Veterinary Surgery, Institute of Veterinary Medicine, Nicolaus Copernicus University in Toruń, Toruń, Poland

*Correspondence: bkempisty@ump.edu.pl

Full list of author information is available at the end of article
} 


\section{Introduction}

The ovary is responsible for the regulation of folliculogenesis as well as the production of sex steroid hormones such as estrogens, progestogens, and androgens [1-3]. Their physiological secretion is strictly controlled by the proper function of the hypothalamus and the pituitary gland, which are liable for the releasing of the gonadotropin-releasing hormone $(\mathrm{GnRH})$, luteinizing hormone ( $\mathrm{LH})$, and follicle-stimulating hormone (FSH) [4-6]. The aromatase is an enzyme that plays a key role in the synthesis of estrogens from the androgens in the ovarian tissue. Its expression is mainly pronounced in the population of ovarian granulosa cells $[7,8]$. Human cumulus cells (CCs) enclose the oocytes and create the separated oocyte-cumulus complexes in the follicle structure. They provide the optimal conditions for bidirectional communication between them and the oocytes, which is crucial for further oocytes maturation $[9,10]$. The effective molecule transferring and signal transmitting between the oocytes and CCs is possible because of specific transmembrane channels - the gap junctions. The gap junctions consist of the transmembrane proteins family members called the connexins. Those channels are required for appropriate oocyte development and successful fertilization [11-14].

The long-term in vitro culture of the cumulus cells could mimic the conditions observed during the preparation to the vitro fertilization (IVF) procedure. The in vitro cultures may bring us an enormous amount of valuable observations that can be applied in the improvements of the currently performed procedures of the IVF [15]. In general, during the preparation to the IVF procedure, the patients undergo controlled ovarian stimulation and the following transvaginal oocyte retrieval. Due to the fact that the CCs are directly connected with the oocyte, the needle collects them in the same cell mass. The immediate (less than $1 \mathrm{~h}$ ) CCs removal after the oocyte collection decreases the final in vitro fertilization success rate. It was established that the highest fertilization rate is achieved when the oocyte rests within the CCs for at least $1 \mathrm{~h}$ after the collection, and the intracytoplasmic sperm injection is performed within $2 \mathrm{~h}$ after the CCs removal [16]. Those results suggest that the oocyte incubation within CCs has a crucial influence on the final treatment outcomes. The exact mechanism of that activity has not been elucidated yet, but it was speculated that CCs could ensure stabilizing the optimal $\mathrm{pH}$ values [16].

It was discovered that the CCs could promote the post-ovulatory mouse oocyte aging through the secretion of the proapoptotic factors such as tumor necrotic factor-alpha and soluble Fas ligand. Moreover, the authors speculated that the application of some sort of specific CCs' apoptosis inhibitors might prevent the aging of mature oocytes in vitro, and as a result, improve the outcomes of assisted-reproduction techniques $[17,18]$. It was suggested that the lower efficiency of the IVF procedure in older patients ( $>40$ years old) might be associated with the increased incidence of the CCs apoptosis [19]. Interestingly, it was proposed that the oocyte itself may inhibit the CCs apoptosis through the secretion of the anti-apoptotic factors. The same authors found that the treatment with the bone morphogenetic proteins 6 and 15 suppresses the CCs apoptosis in vitro [20].

The TP53, BAX, and CASP9 genes and their encoded proteins are known from their intracellular proapoptotic activities [21-23]. Programmed cell death (apoptosis) is a multi-stage, strictly regulated process that controls the physiological cell life cycle in multicellular organisms. The apoptosis balances the constant cell divisions in the human body. A dysregulation in the cell division-death proportions is a common feature of multiple neoplastic diseases [24]. Some stressors like DNA damage can initiate the apoptotic cascade. When the DNA cannot be repaired by the intracellular genome controlling mechanisms, the cell should activate the programmed cell death cascade that leads to the phosphorylation of the p53 protein, which is encoded by the TP53 gene $[25,26]$. Briefly, the activated p53 protein initiates the activation of BAX/BAK proteins, the members of the BCL2 family, which are capable of increasing the permeability of the mitochondrial membranes. As a consequence of those actions, the cytochrome $\mathrm{C}$ molecules are released to the cytoplasm, where they activate the caspase-9 sequence, which eventually leads to cell demolition [26].

The long-term in vitro cultures tend to imitate the CCs' life cycle. Our study aimed to confirm the expression of the above-mentioned proapoptotic genes in the human CCs and assess the dynamics of changes in their expression after 7, 15, and 30 days of in vitro cultivation. The experience gained from the in vitro experiments may be applied in the protocols used in the assisted reproductive technology.

\section{Material and methods \\ The study population and CCs collection}

The study group consists of 12 patients, aged 18-40, diagnosed with infertility. The recruited patients underwent controlled ovarian hyperstimulation and the following IVF procedure in the Department of Infertility and Reproductive Endocrinology, Poznań University of Medical Sciences, Poland. To induce ovarian hyperstimulation, patients were treated with recombinant FSH (Gonal F, Merck Serono) and highly purified menotropin (Menopur, Ferring). The pituitary releasing was blocked by the Cetrorelix's injection (Cetrotide, Merck Serono) - the GnRH antagonist. Finally, the ovulation was stimulated by the injection of $6500 \mathrm{U}$ of choriogonadotropin alfa (Ovitrelle, Merck-Serono). 
After the transvaginal oocyte collection, oocyte-cumulus complexes (COCs) were isolated for further IVF preparation procedures. Then, the collected COCs were denuded using $800 \mathrm{IU} / \mathrm{mL}$ of HYASE-10X. Technician isolated CCs from the multiple follicles, then the obtained CCs were pooled. The collected samples were immediately transferred to the laboratory for further analysis.

\section{Long-term in vitro culture conditions}

Afterward, isolated cells were washed twice with the culture medium and centrifuged (200 x $\mathrm{g}$ for 10 min). The basal culture medium consisted of Dulbecco's Modified Eagle's Medium (DMEM), (Sigma; Merck KGaA, Darmstadt, Germany) supplemented with $10 \mathrm{mg} / \mathrm{ml}$ gentamicin (Invitrogen; Thermo Fisher Scientific, Inc.), 2\% fetal bovine serum (FBS; Sigma; Merck KGaA), 4 mM L glutamine (stock 200 mM, Invitrogen; Thermo Fisher Scientific, Inc., Waltham, MA, USA), 10,000 U/ml penicillin and $10,000 \mu \mathrm{g} / \mathrm{ml}$ streptomycin (Invitrogen; Thermo Fisher Scientific, Inc.).

CCs were cultured at $37^{\circ} \mathrm{C}$ in $5 \%$ CO2/95\% air atmosphere in the 6-well flat-bottom culture plates for 30 days. The culture medium was changed every 72-75 hours. Cells for the analysis were harvested on day 7 th, 15 th, and 30 th of in vitro culture. When the culture reached about $90 \%$ confluence, the cells were detached from the plate by 1-2 min incubation with $0.05 \%$ trypsin-EDTA (Invitrogen; Thermo Fisher Scientific, Inc.), and the first time passaged. The cells harvested on the 7th day are treated as a reference, representing the short-term culture; those harvested on the 15th day of the culture visualize the first passage's effect. On the 30th day, the culture was discontinued.

\section{RNA isolation methods}

The harvested cells were used as a material for RNA isolation. The RNA was isolated using the protocol of the modified method of Chomczyński and Sacchi [27]. The CCs were added to the $1 \mathrm{ml}$ of monophasic guanidine thiocyanate and phenol solution (TRI Reagent $囚$, Sigma; Merck KGaA). The phase separation was performed using the chloroform solution. Then, the samples were centrifuged. After the centrifugation, the upper phase was collected. The RNA purification was performed with the 2 propanol (Sigma; Merck KGaA, catalog number I9516). In the next step, RNA samples were washed with $75 \%$ ethanol, dried, and resuspended in $20 \mu \mathrm{l}$ of pure water.

\section{Reverse transcription-quantitative polymerase chain reaction (RT-qPCR) analysis}

Isolated RNA samples were used to perform reverse transcription. The reverse transcription was conducted using the RT2 First Stand kit-330401 (SABiosciences; Frederick, MD, USA) and Verler- imer 96-well thermocycler. In the next step, the real-time PCR was performed - $2 \mu \mathrm{L}$ of the obtained cDNA solution was mixed with the $18 \mu \mathrm{L}$ of a detection dye QuantiTect $\AA$ SYBR Green PCR (Master Mix Qiagen GmbH, Hilden, Germany) and sequence-specific primers. The reaction was conducted using a LightCycler real-time PCR system (Roche Diagnostics $\mathrm{GmbH}$, Mannheim, Germany). The relative gene expression in the biological samples was assessed in triplicate using the relative quantification method. The $\beta$-actin (ACTB) gene expression was used as an endogenous control.

\section{Ethical approval}

The research related to human use has been complied with all the relevant national regulations, institutional policies and in accordance the tenets of the Helsinki Declaration, and has been approved by the Poznań University of Medical Sciences Bioethical Committee with the resolution no. 1290/18.

\section{Informed consent statement}

Informed consent has been obtained from all individuals included in this study.

\section{Results}

We assessed the relative BAX, CASP9, and TP53 genes mRNA expression in the long-term CCs cultures, after 15 and 30 days of cultivation in reference to values measured in cells harvested on the 7 th day of the in vitro cultivation. The results are shown in Figure 1. The relative expression values are presented as $\log (2)$ fold changes (FC), where the $\mathrm{x}$-fold change in gene expression is expressed as $2^{\log (2) \mathrm{FC}}=\mathrm{x}$-fold.

The cells adhered to the plastic wells very quickly - just after a few hours of in vitro cultivation. Initially, the CCs were star-like shaped, but they gradually changed their shape during the culture duration - at the end, the observed CCs were slightly elongated.

The expression of the apoptotic genes was detected in every biological sample collected throughout the culture period. The relative expression of the examined genes was decreased in every single analyzed time point compared to the reference values.

The highest relative decline in the number of detected gene copies was noted in the samples harvested on the cultivation's 15th day. A similar decrease in the relative expression levels was observed for all analyzed proapoptotic genes. Then, in contrast to those results, the rising tendency was noted. Nonetheless, the observed upregulation was less pronounced than the primary decline.

The most prominent decrease on the 15th day of the culture, amongst the examined genes, was observed in TP53 expression; the decline exceeded $2^{4}$ (i.e., 16-fold). The reduction in the BAX and CASP9 relative expression was almost identical and reached a 10 -fold decrease. 


\section{Relative gene expression}
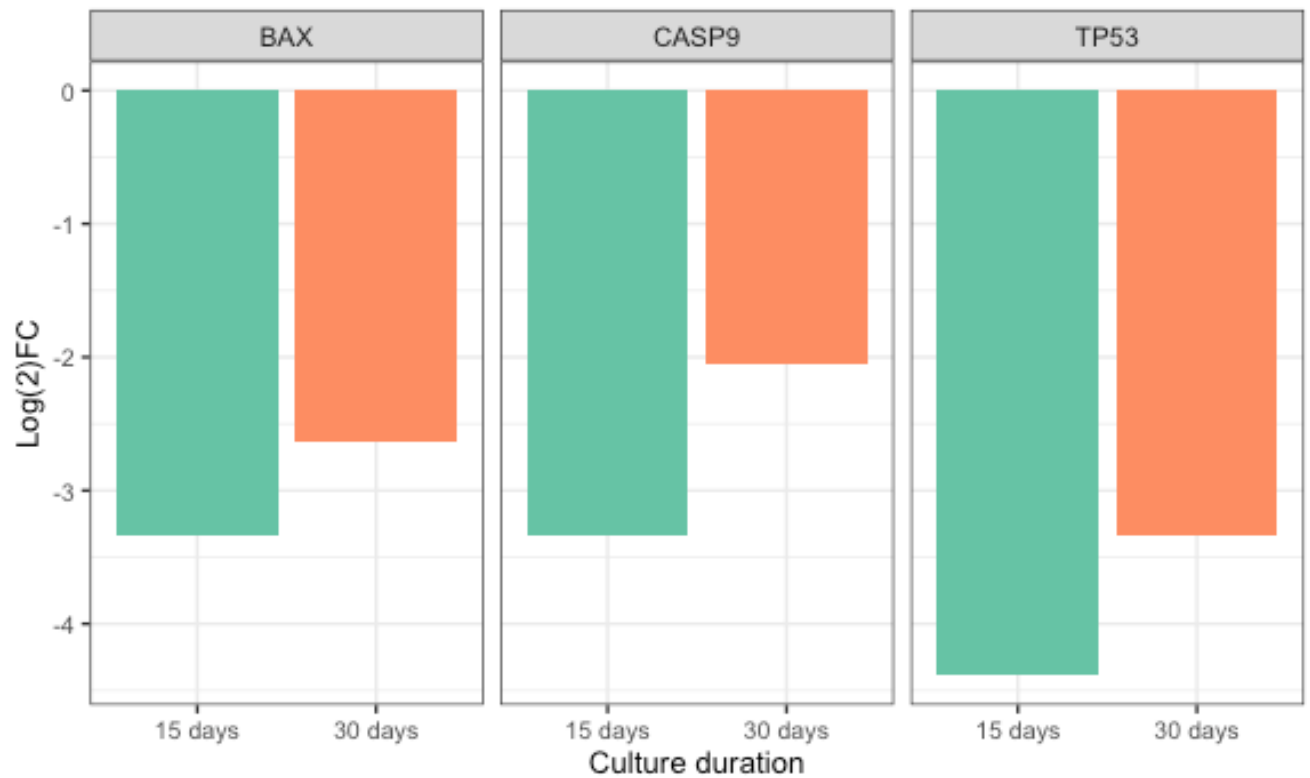

Culture duration

15 days

30 days

FIGURE 1 The structure of the relative changes in the expression of BAX, CASP9, and TP53 mRNA in the human cumulus cells (hCCs) collected after 15 and 30 days of in vitro cultivation. The values are presented as gene expression fold changes on the logarithmic scale with a base of two. Fold changes were calculated in reference to 7 days in vitro cultured hCCs

On the 30th day of the culture, the relative expression of the TP53 continued to be the lowest amongst the analyzed genes. However, the relative increase in its values between the 15 th and the 30 th day of cultivation was the highest. At the end of the culture, the CASP9 relative expression level exhibited the lowest decline compared to its reference values (4-fold decrease).

\section{Discussion}

Our study confirmed that the expression of the following proapoptotic genes - BAX, CASP9, and TP53 - is detectable and uninterrupted throughout the long-term in vitro cultivation. The analyzed genes are the members of the proapoptotic genes family. The apoptotic cascade is initiated by several cellular stressors, which cause the DNA damage that promote the activation of the p53 protein (the protein encoded by the TP53 gene) [28]. In situations when the exposition to those stressors occurs, its expression is markedly upregulated, which triggers the next steps of the apoptotic cascade [21]. Nonetheless, it should be highlighted that the very low expression of the p53 protein is common for the unstressed somatic cells, the possible disturbances in its expression could lead to the occurrence of the malignancy [24]. Although the p53 protein expression in normal conditions is almost undetectable, the relative levels of the TP53 mRNA are much higher $[26,29]$. That fact raises the question of how that phenomenon could be explained? There is an additional cellular mechanism that regulates the p53 protein intracellular levels. The excess of that protein becomes a target for proteasomal degrada- tion [30,31]. Analyzing the result of this study, we should be conscious of these intracellular regulations. Under normal circumstances, the increased p53 protein concentration stimulates the activity of the proapoptotic agents - BAX/BAK - and suppresses the actions of pro-survival BCL-2 proteins [32]. Those stimuli unleash the caspase cascade pathway, which is initiated by the caspase-9 (encoded by the CASP9 gene) [26]. Those regulations allowed us to hypothesize that similar apoptotic genes expression patterns should be expected in the long-term cultured CCs. We observed the simultaneous, synchronized fluctuations in relative transcripts levels. When the expression of TP53 diminished, also the expression of the other analyzed proapoptotic genes was downregulated. Similar outcomes were noted in the last studied period - between the 15th and 30th day of the cultivation - when the relative expression of the TP53 represented a rising tendency, the levels of other transcripts were also upregulated in reference to their recent values.

Assessing the influence of the other external factors on the dynamics of changes in the relative expression of the analyzed genes, special attention should be paid to the cell cultivation conditions. The reference values represent the 7th day of the culture. The second analyzed time point corresponds with the term of the first cell passage. The last interval shows us the conditions observed after the long-term in vitro cultivation. We did not observe any upregulation in the apoptotic genes expression after the first passage, which could suggest that the passaging does not promote the initiation of programmed cell death. All cell cultures were main- 
tained under the same conditions during the study period, which allows us to compare the differences in the relative expression of the analyzed genes.

Leon et al. analyzed the levels of the TP53 and BAX mRNA in the equine oocyte-cumulus complexes. They divided the collected COCs into two groups - morphologically healthy cells and those with lower viability or the features of atresia. The transcripts levels were assessed in the immature oocytes and $\mathrm{CCs}$, and the cells after the in vitro maturation. They noted the significant upregulation in BAX mRNA levels in the less viable CCs compared to morphologically healthy ones in the group of immature cells. Moreover, the TP53 expression in healthy oocytes was significantly higher compared to healthy CCs [33] Fiali et al. analyzed the BAX and BCL-2 mRNA concentrations in COCs collected in women diagnosed with polycystic ovary syndrome. According to their results, BAX mRNA levels did not differ significantly between the CCs associated with the mature oocytes compared to those associated with immature ones. They observed the significantly increased expression of the anti-apoptotic BCL-2 mRNA in the CCs associated with mature oocytes. Furthermore, they found the increased BCL-2 mRNA levels in CCs that enclose the fertilized oocytes [34].

The mouse double minute 2 homolog (MDM2) is an ubiquitin ligase that regulates the proteasomal degradation of the p53 protein [26]. Haraguchi et al. reported that $\mathrm{p} 53$ protein could be responsible for the impairment of the oocyte maturation, which, as a consequence, leads to lower fertility in the murine models. The MDM2 (negative regulator of p53' expression) is crucial for the optimal fertilization rate in mouse. Interestingly, the MDM2 levels in CCs are also positively associated with infertility treatment outcomes in humans [35].

It was suggested that the decreased fertility in the older patients could be partially associated with the disruption in the functioning of the CCs. CCs obtained from those patients presented a higher apoptosis incidence [19]. The in vitro experiments open new perspectives for the studies focused on molecules that could be applied to prevent the CCs apoptosis. Scaruffi et al. analyzed the GnRH treatment's influence on the apoptosis rate in the human oocytes and CCs. They assessed post-treatment changes in the expression of several proapoptotic genes. However, they did not observe any differences between the treated cells and the controls [36]. Moreover, it was noted that the expression of proapoptotic genes such as TP53 and CASP3 in the rabbit COCs during the in vitro maturation could be successfully suppressed using antioxidant agents such as an $\alpha$-Tocopherol [37].

In summary, the expression of the following proapoptotic genes - BAX, CASP9, TP53 - is detectable in the long-term CCs cultures throughout the whole duration of the in vitro cultivation. That fact suggests that the cells maintain the ability to control and initiate programmed cell death mechanisms during the study period. The dynamics of changes in the expression patterns of the various proapoptotic genes was almost identical. The early relative downregulation was inverted in the last culture period. The long-term in vitro culture of human CCs can be used as a model for testing the efficacy of substances that could suppress the expression of the proapoptotic genes in COCs obtained from the patients diagnosed with infertility and, as a consequence, increase the chances for the successful fertilization.

\section{Acknowledgements}

This publication and its results are an outcome of a cooperation between Poznan University of Medical Sciences (Poznań, Poland) and the Polish Ministry of Science and Higher Education, with Cellivia 3 SA (Poznań, Poland), as a part of the "Professional PhD" program.

\section{Corresponding author}

Bartosz Kempisty Ph.D., Department of Histology and Embryology, Department of Anatomy, Poznań University of Medical Sciences, 6 Święcickiego St., 60-781 Poznań, Poland Tel./Fax: +48 618546567 /+4861 8546568, e-mail: bkempisty@ump.edu.pl.

\section{Conflict of interest statement}

The authors declare they have no conflict of interest.

\section{References:}

1. Rimon-Dahari N, Yerushalmi-Heinemann L, Alyagor L, Dekel N. Ovarian folliculogenesis. Results Probl Cell Differ. 2016;58:167-90; DOI:10.1007/978-3-319-31973-5_7

2. Yang DZ, Yang W, Li Y, He Z. Progress in understanding human ovarian folliculogenesis and its implications in assisted reproduction. J Assist Reprod Genet. 2013;30:213-19; DOI:10.1007/s10815-013-9944-x.

3. Franks S, Hardy K. Androgen action in the ovary. Front Endocrinol (Lausanne). 2018;9:452; DOI:10.3389/fendo.2018.00452.

4. Stamatiades GA, Carroll RS, Kaiser UB. GnRH - A Key Regulator of FSH. Endocrinology. 2019;160:57-67; DOI:10.1210/en.2018-00889.

5. Kaprara A, Huhtaniemi IT. The hypothalamus-pituitary-gonad axis: Tales of mice and men. Metabolism. 2018;86:3-17; DOI:10.1016/j. metabol.2017.11.018.

6. Miller WL, Shafiee-Kermani F, Strahl BD, Huang HJ. The nature of FSH induction by GnRH. Trends Endocrinol Metab. 2002;13:257-63. DOI:10.1016/S1043-2760(02)00614-8.

7. Barbieri RL, McShane PM, Ryan KJ. Constituents of cigarette smoke inhibit human granulosa cell aromatase. Fertil Steril. 1986;46:232-6; DOI:10.1016/s0015-0282(16)49517-8.

8. Yang F, Ruan YC, Yang YJ, Wang K, Liang SS, Han Y Bin, Teng XM, Yang JZ. Follicular hyperandrogenism downregulates aromatase in luteinized granulosa cells in polycystic ovary syndrome women. Reproduction. 2015;150:289-96; DOI:10.1530/REP-15-0044

9. Byskov AG, Yding Andersen C, Hossaini A, Guoliang X. Cumulus cells of oocyte-cumulus complexes secrete a meiosis-activating substance when stimulated with FSH. Mol Reprod Dev. 1997;46:296-305; DOI:10.1002/ (SICI)1098-2795(199703)46:3<296::AID-MRD8>3.0.CO;2-K.

10. Dumesic DA, Meldrum DR, Katz-Jaffe MG, Krisher RL, Schoolcraft WB. Oocyte environment: Follicular fluid and cumulus cells are critical for oocyte health. Fertil Steril. 2015;103:303-16; DOI:10.1016/j. fertnstert.2014.11.015.

11. Kidder GM, Mhawi AA. Gap junctions and ovarian folliculogenesis. Reproduction. 2002;123:613-20; DOI:10.1530/rep.0.1230613.

12. Feng G, Shi D, Yang S, Wang X. Co-culture embedded in cumulus clumps promotes maturation of denuded oocytes and reconstructs gap junctions between oocytes and cumulus cells. Zygote. 2013;21:231-7; DOI:10.1017/S0967199412000305.

13. Zhou CJ, Wu SN, Shen JP, Wang DH, Kong XW, Lu A, Li YJ, Zhou HX, Zhao YF, Liang CG. The beneficial effects of cumulus cells and oocyte-cumulus cell gap junctions depends on oocyte maturation and fertilization methods in mice. PeerJ. 2016;4:e1761; DOI:10.7717/peerj.1761. 
14. Santiquet NW, Develle Y, Laroche A, Robert C, Richard FJ. Regulation of gap-junctional communication between cumulus cells during in vitro: Maturation in swine, a gap-FRAP study. Biol Reprod. 2012;87:46; DOI:10.1095/biolreprod.112.099754.

15. Chermuła B, Kranc W, Jopek K, Budna-Tukan J, Hutchings G, Dompe C, Moncrieff L, Janowicz K, Józkowiak M, Jeseta M, Petitte J, Mozdziak P, Pawelczyk L, Spaczyński RZ, Kempisty B. Human Cumulus Cells in Long-Term In Vitro Culture Reflect Differential Expression Profile of Genes Responsible for Planned Cell Death and Aging-A Study of New Molecular Markers. Cells. 2020;9:1265; DOI:10.3390/cells9051265.

16. Hickman CFL, Campbell A, Fishel S. Optimising the timing between oocyte collection, cumulus removal and insemination by ICSI or IVF. Fertil Steril. 2011;96; DOI:10.1016/j.fertnstert.2011.07.305.

17. Kong QQ, Wang J, Xiao B, Lin FH, Zhu J, Sun GY, Luo MJ, Tan JH. Cumulus cell-released tumor necrosis factor (TNF)-a promotes post-ovulatory aging of mouse oocytes. Aging (Albany NY). 2018;10:1745-57; DOI:10.18632/aging.101507.

18. Zhu J, Zhang J, Li H, Wang TY, Zhang CX, Luo MJ, Tan JH. Cumulus cells accelerate oocyte aging by releasing soluble Fas Ligand in mice. Sci Rep. 2015;5:8683; DOI:10.1038/srep08683.

19. Lee KS, Joo BS, Na YJ, Yoon MS, Choi OH, Kim WW. Cumulus cells apoptosis as an indicator to predict the quality of oocytes and the outcome of IVF-ET. J Assist Reprod Genet. 2001;18:490-8; DOI:10.1023/A:1016649026353.

20. Hussein TS, Froiland DA, Amato F, Thompson JG, Gilchrist RB. Oocytes prevent cumulus cell apoptosis by maintaining a morphogenic paracrine gradient of bone morphogenetic proteins. J Cell Sci. 2005;118:525768; DOI:10.1242/jcs.02644.

21. Fridman JS, Lowe SW. Control of apoptosis by p53. Oncogene 2003;22:9030-40; DOI:10.1038/sj.onc.1207116.

22. Cardone MH, Roy N, Stennicke HR, Salvesen GS, Franke TF, Stanbridge E, Frisch S, Reed JC. Regulation of cell death protease caspase-9 by phosphorylation. Science. 1998;282:1318-21; DOI:10.1126/ science.282.5392.1318.

23. McArthur K, Whitehead LW, Heddleston JM, Li L, Padman BS, Oorschot V, Geoghegan ND, Chappaz S, Davidson S, Chin HS, Lane RM, Dramicanin M, Saunders TL, Sugiana C, Lessene R, Osellame LD, Chew TL, Dewson G Lazarou M, Ramm G, Lessene G, Ryan MT, Rogers KL, Van Delft MF, Kile BT. BAK/BAX macropores facilitate mitochondrial herniation and mtDNA efflux during apoptosis. Science. 2018;359:eaao6047; DOI:10.1126/ science.aao6047.

24. Wong RSY. Apoptosis in cancer: From pathogenesis to treatment. J Exp Clin Cancer Res. 2011;30:87; DOI:10.1186/1756-9966-30-87.

25. Polyak K, Xia Y, Zweier JL, Kinzler KW, Vogelstein B. A model for p53-induced apoptosis. Nature. 1997;389;300-5; DOI:10.1038/38525.

26. Aubrey BJ, Kelly GL, Janic A, Herold MJ, Strasser A. How does p53 induce apoptosis and how does this relate to p53-mediated tumour suppression? Cell Death Differ. 2018;25:104-113; DOI:10.1038/cdd.2017.169.

27. Chomczynski P, Sacchi N. Single-step method of RNA isolation by acid guanidinium thiocyanate-phenol-chloroform extraction. Anal Biochem. 1987;162:156-9; DOI:10.1016/0003-2697(87)90021-2.

28. Pflaum J, Schlosser S, Müller M. P53 family and cellular stress responses in cancer. Front Oncol. 2014;4:285; DOI:10.3389/fonc.2014.00285.

29. Reich NC, Levine AJ. Growth regulation of a cellular tumour antigen, p53, in nontransformed cells. Nature. 1984;308:199-201; DOI:10.1038/308199a0

30. Haupt Y, Maya R, Kazaz A, Oren M. Mdm2 promotes the rapid degradation of p53. Nature. 1997;387:296-9; DOI:10.1038/387296a0.

31. Shieh SY, Ikeda M, Taya Y, Prives C. DNA damage-induced phosphorylation of p53 alleviates inhibition by MDM2. Cell. 1997;91:325-34 DOI:10.1016/S0092-8674(00)80416-X.

32. Westphal D, Dewson G, Czabotar PE, Kluck RM. Molecular biology of Bax and Bak activation and action. Biochim Biophys Acta - Mol Cell Res. 2011;1813:521-31; DOI:10.1016/j.bbamcr.2010.12.019.

33. Leon PMM, Campos VF, Kaefer C, Begnini KR, Mcbride AJA, Dellagostin OA, Seixas FK, Deschamps JC, Collares T. Expression of apoptotic genes in immature and in vitro matured equine oocytes and cumulus cells. Zygote. 2013;21:279-85; DOI:10.1017/S0967199411000554.

34. Filali M, Frydman N, Belot MP, Hesters L, Gaudin F, Tachdjian G, Emilie D, Frydman R, Machelon V. Oocyte in-vitro maturation: BCL2 mRNA content in cumulus cells reflects oocyte competency. Reprod Biomed Online. 2009;19 Suppl 4:4309; DOI:10.1016/s1472-6483(10)61071-1.

35. Haraguchi H, Hirota Y, Saito-Fujita T, Tanaka T, Shimizu-Hirota R, Harada M, Akaeda S, Hiraoka T, Matsuo M, Matsumoto L, Hirata T, Koga K, Wada-Hiraike O, Fujii T, Osuga Y. Mdm2-p53-SF1 pathway in ovarian granulosa cells directs ovulation and fertilization by conditioning oocyte quality. FASEB J. 2019;33:2610-20; DOI:10.1096/fj.201801401R.
36. Scaruffi P, Stigliani S, Cardinali B, Massarotti C, Lambertini M, Sozzi F Dellepiane C, Merlo DF, Anserini P, Del Mastro L. Gonadotropin releasing hormone agonists have an anti-apoptotic effect on cumulus cells. Int J Mol Sci. 2019;20:6045; DOI:10.3390/ijms20236045.

37. Arias-Álvarez M, Garciá-Garciá RM, López-Tello J, Rebollar PG, Gutiérrez-Adán A, Lorenzo PL. $\alpha$-Tocopherol modifies the expression of genes related to oxidative stress and apoptosis during in vitro maturation and enhances the developmental competence of rabbit oocytes. Reprod Fertil Dev. 2018;30:1728-38; DOI:10.1071/RD17525. 